\title{
A Dynamic Study of CO Oxidation on
}

\section{Supported Platinum}

Catalytic oxidation of $\mathrm{CO}$ on alumina-supported platinum was studied in a tubular isothermal reactor with applied concentration transients. A completely automated reactor system capable of switching frequencies as high as $0.2 \mathrm{~Hz}$ was constructed.

Concentration cycling resulted in reaction rates that were much higher than the maximum rate achievable at steady-state operation. Mapping of the time-averaged carbon dioxide production rate in the time-period duty-fraction plane, resulted in a unique global maximum. We find that the maximum in rate occurs when the switching times are comparable to the characteristic time of the surface reaction. Results of our experiments also rule out significant contribution from the EleyRideal mechanism at the temperature range of this work (below $120^{\circ} \mathrm{C}$ ).

\author{
Yoav Barshad and \\ Erdogan Gulari \\ Department of Chemical Engineering \\ The Universily of Michigan \\ Ann Arbor, Ml $\mathbf{4 8 1 0 9}$
}

\section{SCOPE}

The fact that periodic operation of catalytic reactors may result in better overall performance has been suggested by many researchers including Douglas (1972) and Bailey (1973, 1977). Most of the work in this area has been theoretical, with the exception of a few experimental studies, among which Cutlip's (1979) work showed the most dramatic rate enhancement.

In this paper the possibility of using a tubular reactor was explored in order to obtain a system time constant of the same order of magnitude as the surface processes. In order to achieve this very short time response a completely automated reactor system was built and the oxidation of $\mathrm{CO}$ on supported platinum was studied with relatively short switching periods (as low as 10 seconds).

\section{CONCLUSIONS AND SIGNIFICANCE}

Periodic operation of a catalytic reactor was extended to switching times significantly shorter than previously reported for this reaction. It is shown that the maximum in conversion occurs at a point where the time period and duty-fraction are comparable to characteristic times of surface phenomena rather than the reactor time constant. The most significant findings are:

1. Periodic feed switching results in time-averaged oxidation rates much higher than the maximum achievable by steady-state operation. The increase can not be explained as being due only to increased surface coverage of oxygen.

2. Experimentally, it is verified that there is a global maximum in conversion in the time-period, duty-fraction plane. The locus of the maximum in conversion moves in a predictable fashion with feed concentration and temperature.

3. Increased rate of reaction is only due to periodic switching of the carbon monoxide feed. We believe that periodic on-off switching of the feed optimizes the reactive $\mathrm{CO}$ surface species at the expense of nonreactive stable species.

4. At the temperatures used in this work, oxidation of $\mathrm{CO}$ proceeds by the Langmuir-Hinschelwood mechanism.

We have also observed that the dependence of the reaction rate on the surface concentration of $\mathrm{CO}$ and $\mathrm{O}_{2}$ is not the same. Sustained oscillations in the conversion occur both during steady-state and periodic operation of the tubular reactor. This study shows the benefits of automated reactors in collecting and analyzing enormous amounts of kinetic data in real time.

\section{INTRODUCTION}

Deliberate periodic operation of chemical reactors for improvements in performance and/or selectivity was discussed by Douglas (1967, 1972), Douglas and Rippin (1966) and extensively studied and reviewed by Bailey $(1973,1977)$. While most of the initial papers in periodic operation were theoretical, in recent years

the number of experimental studies has increased considerably. One of the first experimental studies in this area was by Denis and Kabel (1970) who studied the periodic operation of a heterogeneous reactor for the vapor phase dehydrogenation of ethanol and observed that adsorption-desorption played a predominant role in the system transients. Oxidation of $\mathrm{SO}_{2}$ on $\mathrm{V}_{2} \mathrm{O}_{5}$ was studied by Unni et al. (1973), where rate improvements of $30 \%$ were achieved. Renken et al. (1974) found the periodic operation of a tubular reactor for ethylene oxidation to be superior to steady state operation. 
Renken et al. (1976) also showed that alternate feeding of ethylene and oxygen to a fixed-bed silver catalyst reactor increased the selectivity toward ethylene oxide while reducing the reactor temperature. Improvements in selectivity or yield in butadiene hydrogenation were reported by Al-Taie and Kershenbaum (1978), who found that improvements of $20 \%$ over the optimal steady-state operation were possible. Bilimoria and Bailey (1978) obtained improvement both in ethane and ethylene yields in hydrogenation of acetylene by periodic feed switching. Forced composition cycling in a fixed-bed ammonia synthesis reactor was investigated by Jain et al. (1982), with improvements of 30 to 50\% compared to steady state. Ammonia synthesis was also investigated by Rinker and Wilson (1982)

Of all the reaction systems, $\mathrm{CO}$ oxidation has been studied in more detail than any other (Cutlip, 1979, 1982; Herz, 1982). Cutlip studied $\mathrm{CO}$ oxidation over $\mathrm{Pt} / \mathrm{Al}_{2} \mathrm{O}_{3}$ catalyst in a gradientless reactor. He has shown that limit cycle oscillations occur during isothermal operation with or without small amounts of hydrocarbons. Most importantly, Cutlip's (1979) work demonstrated that an increase in conversion by as much as a factor of 20 was possible by periodically switching the feed between $\mathrm{CO}$ and $\mathrm{O}_{2}$.

Periodic operation of chemical reactors has also become a reality on a very large scale during the last two years. All 1982 and later models of General Motors Corporation cars have a periodicallyoperated catalytic converter. The feed is switched at a frequency of $2 \mathrm{~Hz}$ between oxygen-rich and lean streams (Herz, 1982). On the homogenous reaction side, a new operation mode for home gas furnaces was developed by American Gas Association Laboratories. Charges of gas and air are admitted at about $60 \mathrm{~Hz}$ into the combustion chamber, where they ignite and burn. Thanks to periodic operation, the actual efficiency of the furnace is $96 \%$ of the theoretical maximum, resulting in a $40 \%$ improvement over conventional furnaces.

The use of transient experiments in catalysis was initially suggested by Tamaru (1965). This technique was successfully utilized by many researchers, including Kobayashi $(1974,1982)$ and Bennett (1976), to obtain a better understanding of the behavior of heterogeneous catalytic reactions. The basic idea is that imposing a well-defined perturbation on the inlet of a catalytic reactor results in a transient which reflects the nature of the sequence of steps that underlies the observed kinetics, rather than the combined response of the individual steps (steady state).

The purpose of this study was to demonstrate the benefits of periodic operation of catalytic reactors on a time scale much shorter than previous studies. Specifically we wanted: 1) to determine the effect of cycling frequency and duty fraction on the time-average conversion, and 2) to explain the position of the maximum average rate point by analysis of the $\mathrm{CO}, \mathrm{O}_{2}$, and $\mathrm{CO}_{2}$ waveforms during step changes and periodic cycling.

A secondary objective was to obtain additional kinetic information not available from steady-state operation or step-up and step-down transient experiments. A tubular reactor with a short time constant was chosen so that we would not be constrained by the residence time in the reactor.

\section{Reaction System}

Apart from its simplicity, the major reason for our choice of $\mathrm{CO}$ oxidation on supported platinum as the reaction to study was the abundance of experimental data available in the literature. Wei (1975) and Engel and Ertl (1979) have given extensive discussions of this reaction system. The following represent the commonly agreed upon elementary steps.

1. $\mathrm{CO}+\mathrm{S} \leftrightarrow \mathrm{CO}-\mathrm{S}$

2. $\mathrm{O}_{2}+2 \mathrm{~S} \leftrightarrow 2(\mathrm{O}-\mathrm{S})$

3. $\mathrm{CO}-\mathrm{S}+\mathrm{O}-\mathrm{S} \rightarrow-\mathrm{CO}_{2}+2 \mathrm{~S}$

4. $\mathrm{CO}+\mathrm{O}-\mathrm{S} \rightarrow \mathrm{CO}_{2}+\mathrm{S}$

where $S$ is a platinum surface site.

Step 1 represents the adsorption of carbon monoxide, which at low temperatures is almost irreversible. Step 2 represents adsorption of oxygen; this step is also almost irreversible at low temperatures.
Steps $s$ and 4 are the surface reactions given by the LangmuirHinschelwood (LH) and Eley-Rideal (ER) mechanisms, respectively.

There is significant disagreement over the relative importance of the LH and ER steps. Dwyer and Bennett (1982) have argued that there is a transition from a modified ER to LH mechanism as the surface coverage of $\mathrm{CO}$ increases. High-resolution infrared studies indicate that it is more probable that adsorbed $\mathrm{O}_{2}$ and adsorbed $\mathrm{CO}$ react at the perimeter of $\mathrm{CO}$ islands (Haaland and Williams, 1982; Sarakany et al., 1983). Studies done at low pressures also favor the LH mechanism (Fair, 1980). The commonly employed assumption of adsorption/desorption equilibrium may not be generally valid for $\mathrm{CO}$ oxidation on platinum, as pointed out by Herz and Marin (1980). They found that they needed to invoke rate-limiting adsorption kinetics to fit $\mathrm{CO}$ oxidation rate data on $\mathrm{Pt} / \mathrm{Al}_{2} \mathrm{O}_{3}$ catalysts at atmospheric pressure. Gland (1982) found that there is a very high probability for formation of oxygen islands in water formation over supported platinum. There is also evidence that the adsorbed oxygen is not mobile, while the adsorbed carbon monoxide diffuses more rapidly on the surface (Haaland and Williams, 1982).

Instabilities in the carbon monoxide/oxygen/platinum system have led to oscillatory phenomena which have been reviewed by Sheintuch (1977). There is some indication that the oscillations may be caused by hydrocarbon impurities (Cutlip and Kenny, 1978), but evidence to the contrary is also present (Tsotsis and Elhaderi, 1982).

The rate of $\mathrm{CO}$ oxidation over platinum presents a rare behavior (Wei, 1975) in the sense that it is first-order with respect to $\mathrm{CO}$ at low gas phase concentrations, goes through an extremum, and becomes -1 at high gas phase concentrations. The so-called inhibiting effect of $\mathrm{CO}$ on the rate can be seen in the following intrinsic rate expression obtained by Voltz (1973):

$$
\text { Rate }=\frac{k_{1}\left(\mathrm{O}_{2}\right)(\mathrm{CO})}{\left[1+k_{2}(\mathrm{CO})\right]^{2}}
$$

\section{EXPERIMENTAL}

\section{Reactor System}

The general-purpose reactor system shown in Figure 1 was used in this work to study catalytic $\mathrm{CO}$ oxidation over $\mathrm{Pt} / \mathrm{Al}_{2} \mathrm{O}_{3}$ pellets. The reactor consisted of a stainless steel tube $1.27 \mathrm{~cm}$ in diameter and $17.8 \mathrm{~cm}$ long, of which $14 \mathrm{~cm}$ was filled with the catalyst pellets. The inlet section of the reactor was filled with glass beads of similar size to that of the catalyst pellets, creating a preheating area for the reactants. In order to make sure that the reactor's building material (304 SS) did not contribute to the reaction, blank runs with glass beads in place of the catalyst pellets were made at the same temperatures and pressure as the actual runs presented in this study. $\mathrm{No} \mathrm{CO}_{2}$ was detected at the outlet.

The reactant flow rates were measured individually with a Kurz mass flow meter (model $500-3$ ). The accuracy was $\pm 2 \%$ of the reading and $\pm 0.5 \%$ of full scale. Repeatability under pressure variations (up to $160 \mathrm{kPa}$ ) was $\pm 0.25 \%$. Response time to $95 \%$ of the final reading was $25 \mathrm{~ms}$. Tubing length was kept to a minimum to prevent distortion of the concentration pulses. The reactor was normally operated at a pressure of $140 \mathrm{kPa}$.

The catalyst used in this study was $0.5 \% \mathrm{Pt}$ supported on alumina in the form of $0.318 \mathrm{~cm}$ pellets. The exposed platinum was found to be $53 \%$, and $95 \%$ of the platinum was deposited in the outer $160 \mathrm{~m}$ by a nonaqueous process. The gases used were $99.99 \% \mathrm{~N}_{2}, 99.6 \% \mathrm{O}_{2}$, and $99 \% \mathrm{CO}$ from Matheson. Since the $\mathrm{CO}$ was not purified, it is important to note that our results using the same catalyst were reproducible within detection limits over a time period of three months, and $900 \mathrm{~L}$ of $\mathrm{CO}$ (STP). This indicates that the catalyst was not being poisoned by either impurities or carbon deposition. In visual checks of the preheater glass beads, no nickel or iron depositions from volatile carbonyls were evident. In all our studies the maximum temperature $\left(120^{\circ} \mathrm{C}\right)$ was lower than the decomposition temperatures for iron carbonyl.

With the flows used $\left(450 \mathrm{~cm}^{3} / \mathrm{min}\right)$, the Reynolds number based on pellet diameter was around 15 , giving an axial Peclet number of 2 . The tubelength-to-pellet-diameter ratio of $\mathbf{4 4}$ gave assurance that backmixing was negligible; however, the low tube-to-pellet-diameter ratio of 4 gave some deviation from plug flow as can be seen in Figure 2. The possibility of mass 


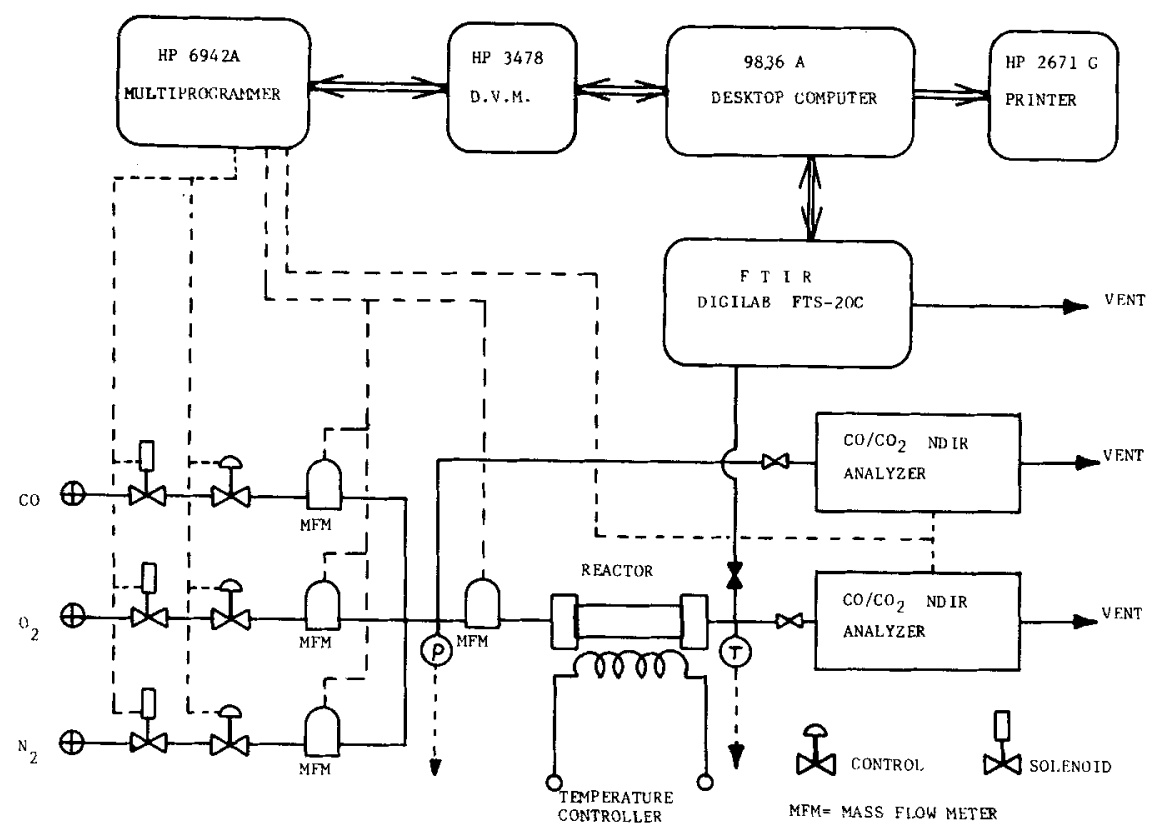

Figure 1. Schematic diagram of the reactor and data acquisition system: - - - analog lines; $=$ digital data; — tubing.

transfer limitations was ruled out theoretically and experimentally. The possibility of temperature variations was investigated using a $0.5 \mathrm{~mm}$ thermocouple the position of which could be changed in the axial direction (from $1.5 \mathrm{~cm}$ down the bed to $9 \mathrm{~cm}$ down the bed) and radially (from wall to wall). Under our operating conditions we could not detect differences of more than $2^{\circ} \mathrm{C}$ in agreement with theoretical calculations following Satterfield's (1981) analysis.

\section{Detection}

Two Infrared Industries IR detectors capable of simultaneously detecting $\mathrm{CO}$ and $\mathrm{CO}_{2}$ were used with a flow-through cell. The volume of the detector cell was found to be $38 \mathrm{~cm}^{3}$; with the given flow rate it presented a characteristic time of 3.5 seconds. The absolute accuracy of the IR detectors was checked with a Digilab FTS-20/C FTIR spectrometer and was found to be $1 \%$ or better over the range of $0-20 \%$ concentration by volume.

\section{Data Acquisition and Operation}

As can be seen in Figure 1, data acquisition was accomplished with an HP-9836A computer via a digital voltmeter (DVM) and a multiprogrammer. The high rate of data processing capability enabled continuous monitoring of the inlet and outlet concentrations of $\mathrm{CO}$ and $\mathrm{CO}_{2}$. In addition, flow rates for individual reactants as well as temperatures and pressures were also accumulated for each experiment. Especially in cases

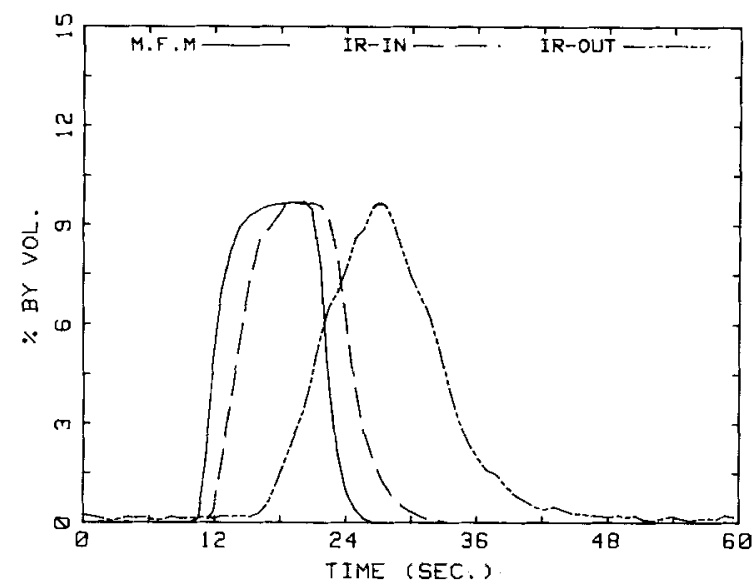

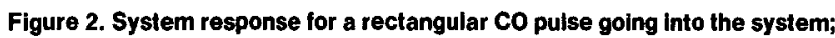
actual readings of the various transducers. Flow rate $=450 \mathrm{~cm}^{3} / \mathrm{min} ;$ M.F.M. $=$ mass flow meter. where keeping track of time is crucial for correct interpretation of the results (transient kinetics), the fact that the computer controls and measures the inlet concentrations and flows is of great advantage. The results are automatically stored on flexible media, and are displayed in graphical form in real time.

The inlet manifold is where the reactants, $\mathrm{CO}$ and $\mathrm{O}_{2}$, are mixed with each other and with the diluent gas (nitrogen). It is adjusted in such a way that whenever one of the reactants is shut off, the $\mathrm{N}_{2}$ flow rate is increased to maintain a constant concentration of the other reactant and a constant total flow. During periodic operation the feed was switched from $10 \% \mathrm{CO}$ in $\mathrm{N}_{2}$ to $10 \% \mathrm{O}_{2}$ in $\mathrm{N}_{2}$ with different time periods. The fraction of this time period in which $\mathrm{CO}$ was flowing is the CO duty-fraction. No measurable pressure variations were noticed during periodic operation, assuring constant residence time and accurate IR measurements.

\section{RESULTS AND DISCUSSION}

\section{Flow Characteristics of the Reactor System}

The most dramatic change that can be imposed on an inlet concentration into a reactor is a step function. The inlet concentration was switched in order to manipulate the surface coverage. To achieve this goal, the void fraction in the reactor system was kept as small as possible to minimize the exponential time constants.

A significant difference between a continuous stirred tank reactor (CSTR) and a tubular reactor is in the sharpness of the concentration gradient that can be imposed. In a CSTR, the concentration profile will always be an exponential with a characteristic time equal to the CSTR residence time. Thus, a CSTR is useful only for periodic operation where the switching time periods are significantly longer than the residence time. For time periods less than twice the residence time, the CSTR will act as a low-pass filter, smoothing out the concentration profile and eliminating surface transients, as demonstrated in Cutlip's (1979) work on the same system. A tubular reactor of comparable volume, on the other hand, can be operated with much shorter time periods without losing the benefits of periodic operation. For this reason, as well as for the sake of simplicity, a tubular reactor was used in our investigation. Even though most of our operation was in the differential reactor mode for periodic operation, the terms "differential" and "integral" modes are not clearly distinguishable. As a result, the kinetic data is interpreted only qualitatively.

In order to characterize the response of our reactor and detection 


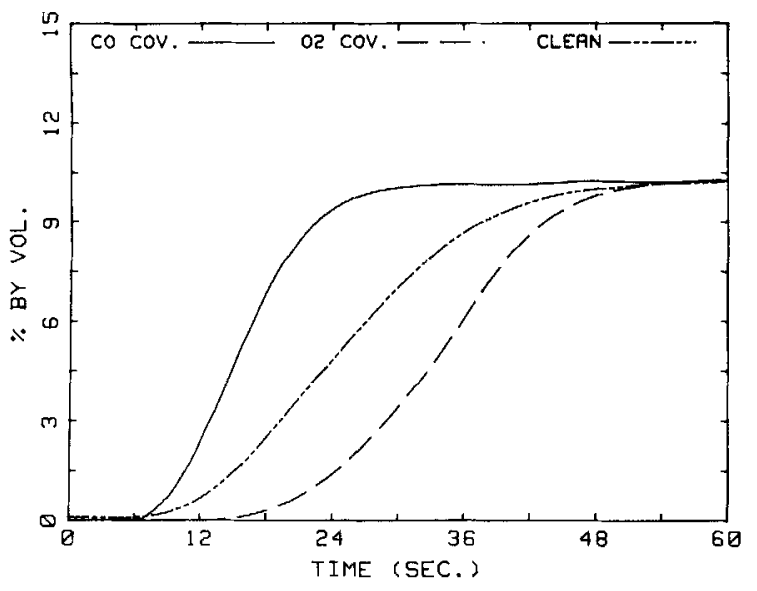

Figure 3. CO step-up response for: 1) CO-covered surface or glass beads packed reactor; 2) clean surface (nelther $\mathrm{CO}$ nor $\mathrm{O}_{2}$ ); 3) $\mathrm{O}_{2}$-covered surface.

system, the reactor was filled with glass beads of the same diameter as the catalyst pellets and a rectangular pulse was imposed on the inlet. The signals of the IR detectors at the inlet and outlet of the reactor were followed as a function of time simultaneously. The $\mathrm{CO}$ response of the reactor system $\left(\mathrm{CO}_{2}\right.$ response is identical) can be seen in Figure 2. Although the response deviates from plug flow, it shows that under nonreacting conditions the response is much faster than any of the transients monitored later $(64 \% \mathrm{CO} / \mathrm{min})$. In normal operation the inlet IR detector was not in series with the reactor as seen in Figure 1, thus pulse-front dispersion was due only to the tubing and the reactor.

\section{Step Response}

The second set of experiments was designed to probe the adsorption and desorption processes on the catalyst surface. The catalyst was reduced in an atmosphere of flowing $\mathrm{CO}$ and $\mathrm{N}_{2}$ at $200^{\circ} \mathrm{C}$ for several hours. The $\mathrm{CO}$ flow was cut off and the $\mathrm{N}_{2}$ flow was continued until no $\mathrm{CO}$ was detected at the outlet. After cooldown to $105^{\circ} \mathrm{C}$, the $\mathrm{CO}$-up response of the reactor was determined as shown in Figure 3. Also seen in Figure 3 are the responses with CO-covered surface and with oxygen-covered surface. The difference between the three is that in the CO-covered surface nothing is adsorbed and the response is identical to that of a reactor filled with glass beads. The CO-down response is identical with the $\mathrm{CO}$-down response in the absence of any catalyst, verifying that at $105^{\circ} \mathrm{C}$, there is no appreciable $\mathrm{CO}$ desorption from platinum. With a clean surface (neither $\mathrm{CO}$ nor $\mathrm{O}_{2}$ adsorbed), the response

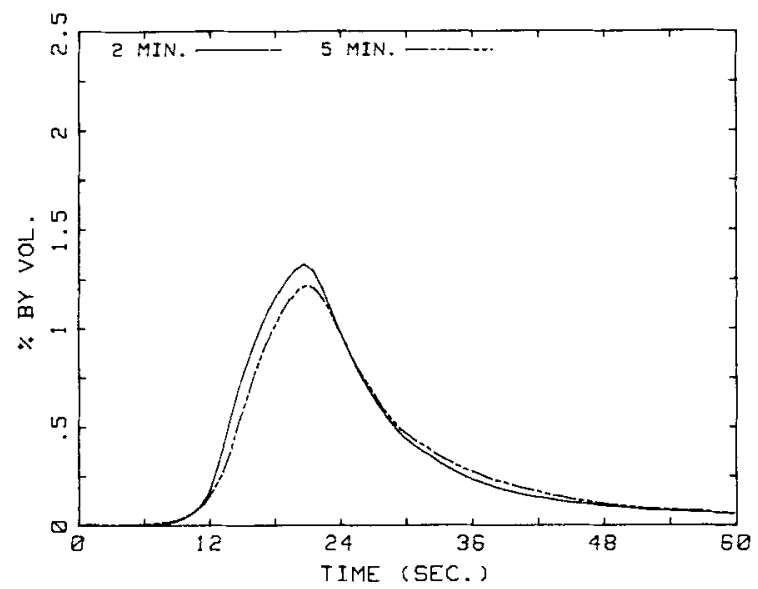

Figure 4. $\mathrm{CO}_{2}$ outlet proflle for a step-up of $10 \% \mathrm{O}_{2}$ into a CO-preireated reactor. Pretreatment: $10 \%$ CO in $\mathrm{N}_{2}$ for 2 hours, then 2- or 5-minute flush with N2.

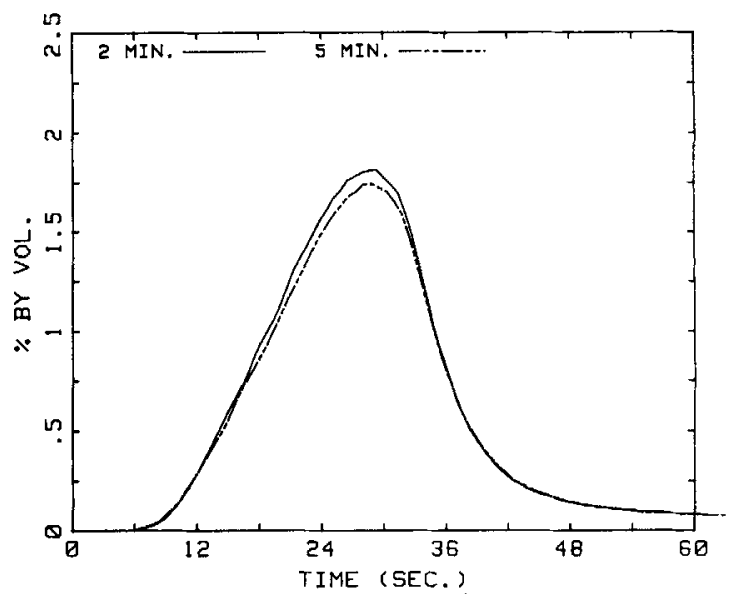

Figure 5. $\mathrm{CO}_{2}$ outlet profile for a $10 \%$ step-up of $\mathrm{CO}$ into an $\mathrm{O}_{2}$-pretreated reactor; $10 \% \mathrm{O}_{2}$ in $\mathrm{N}_{2}$ lor 2 hours, then 2- or $\mathbf{5}$-minute flush with $\mathbf{N}_{2}$.

is slower due to a portion of the $\mathrm{CO}$ being adsorbed on the clean surface. In the third case, where the surface had been pretreated with $\mathrm{O}_{2}$, the $\mathrm{CO}_{2}$ response is the slowest. The reason for this is that $\mathrm{CO}$ is consumed by two mechanisms, adsorption and reaction with $\mathrm{O}_{2}$. The area enveloped between the $\mathrm{CO}$ response for glass beads and for clean catalyst was integrated to give $2.3 \times 10^{-4} \mathrm{~mol} \mathrm{CO}$ adsorbed on the catalyst.

The third set of experiments was designed to provide information about the mechanism of $\mathrm{CO}$ oxidation. After treating the catalyst with $\mathrm{CO}$, the CO flow was cut off and the reactor was flushed with $\mathrm{N}_{2}$. After flushing, the $\mathrm{CO}$ and $\mathrm{CO}_{2}$ responses to a step input of $\mathrm{O}_{2}$ were monitored. In Figure 4, the $\mathrm{CO}_{2}$ response for a 2-minute and a 5-minute flush is shown. There is no detectable $\mathrm{CO}$ in the output. Figure 5 shows the result of the complementary experiment: the surface is pretreated with $\mathrm{O}_{2}$, and the $\mathrm{CO}$ and $\mathrm{CO}_{2}$ response to a step input of $\mathrm{CO}$ is monitored. Again the rise of $\mathrm{CO}_{2}$ concentration in the output is very rapid and is as fast as the rise in the CO concentration. The results for 2 -minute and 5 -min flushing differ by only $5 \%$, indicating very strong $\mathrm{CO}$ and $\mathrm{O}_{2}$ chemisorption at this temperature. By comparing Figure 4 with Figure 5 it can be seen that for both $\mathrm{CO}$ and $\mathrm{O}_{2}$ pretreatment, the longer flushing time decreased the amount of $\mathrm{CO}_{2}$ formed by $3 \%$ for the $\mathrm{CO}$-pretreated surface and by about $5 \%$ for the oxidized surface. This shows that not all of the $\mathrm{CO}$ and $\mathrm{O}_{2}$ is irreversibly adsorbed, in agreement with Dwyer and Bennett (1982). The areas below the curves were integrated giving the following results: the amount of $\mathrm{CO}_{2}$ produced with the $\mathrm{O}_{2}$-covered surface was 1.77 times the amount produced with the CO-covered surface. $9.5 \times 10^{-5} \mathrm{~mol}$ of $\mathrm{CO}_{2}$ were produced for the $\mathrm{O}_{2}$-covered surface and $5.4 \times 10^{-5} \mathrm{~mol}$ for the $\mathrm{CO}$ -

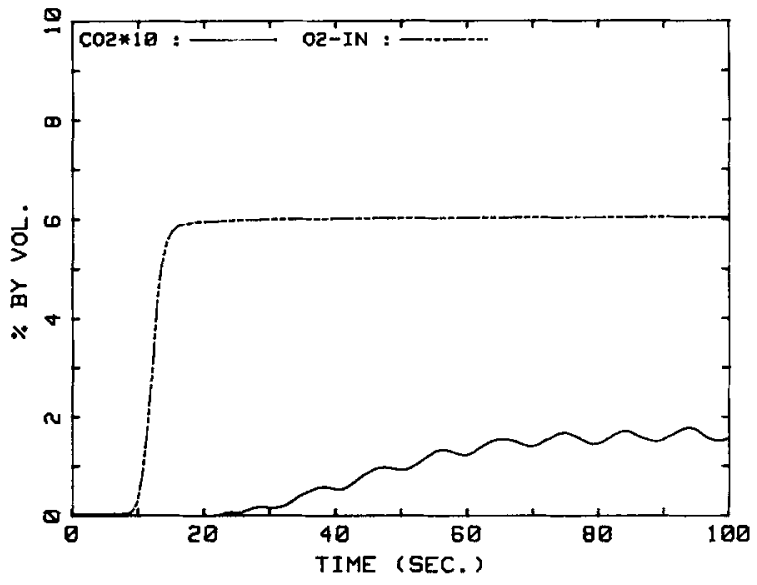

Figure 6. $\mathrm{CO}_{2}$ response to a step-up of $\mathrm{O}_{2}$ from $\mathrm{O}$ to $6 \%$ in the presence of $11.2 \% \mathrm{CO} ; \mathrm{T}=105^{\circ} \mathrm{C}$. 


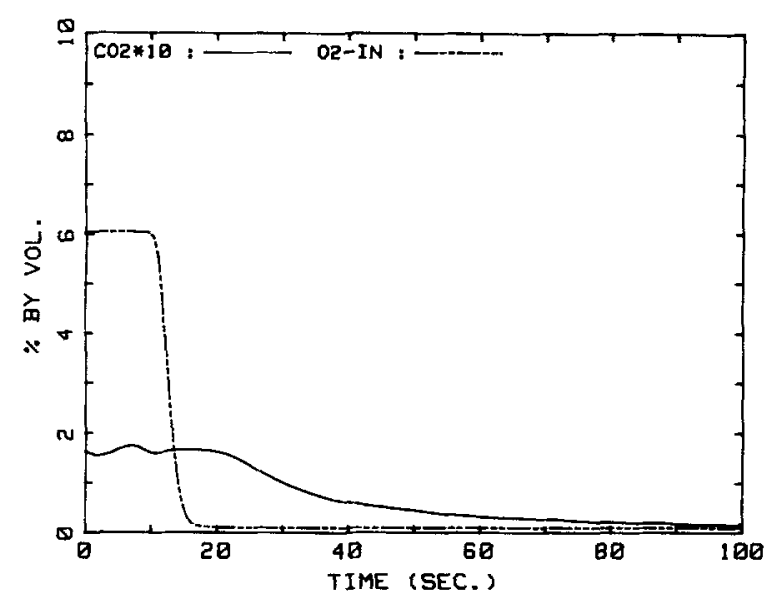

Figure 7. $\mathrm{CO}_{2}$ response to an $\mathrm{O}_{2}$ step-down from $6 \%$ to $\mathrm{O}$ in the presence of $11.2 \% \mathrm{CO} ; \mathrm{T}=105^{\circ} \mathrm{C}$.

covered surface. It was found by means of room-temperature $\mathrm{O}_{2}$ titration that $53 \%$ of the platinum was exposed

Figures 6 and 7 show the $\mathrm{CO}_{2}$ responses to a step-up and stepdown of oxygen in the presence of a constant stream of $\mathrm{CO}$. In the up response, there is a slow increase in the $\mathrm{CO}_{2}$ production rate with a time constant on the order of 30 seconds. The $\mathrm{O}_{2}$ step-down response of $\mathrm{CO}_{2}$ production is about twice as fast as the $\mathrm{O}_{2}$ step-up response shown in Figure 6 . Repeating the same experiment at a different temperature results only in a difference in the characteristic time constant, longer for low temperatures, shorter for high temperatures

Figures 8, 9, and 10 show $\mathrm{CO}_{2}$ response to a $\mathrm{CO}$ step-up and step-down in the presence of a constant stream of oxygen. From Figure 8 we see that switching $\mathrm{CO}$ on results in a rapid production of $\mathrm{CO}_{2}$ which reaches a maximum of $0.7 \%$ concentration in the output and then comes down to a steady-state value of $0.21 \%$. There are small secondary oscillations imposed on the overall $\mathrm{CO}_{2}$ concentration curve. These oscillations are stable sinusoids with a period of almost $9 \mathrm{~s}$. Figure 9 shows results of the same experiment as that presented in Figure 8 (performed under different conditions), to emphasize the overshoot/undershoot behavior of this transient response (similar observation was made by Herz 1983). The recovery from the undershoot has a relatively large time constant of 40-50 seconds. In all of our CO step-up experiments, we observed this distinct overshoot/undershoot and slow recovery, with the superimposed secondary oscillations, to the steady-state reaction rate. The CO step-down experiment shown in Figure 10 is also very similar to Figure 8 in that as soon as the $\mathrm{CO}$ flow is cut off, there is a very rapid increase in the $\mathrm{CO}_{2}$ production. The $\mathrm{CO}_{2}$

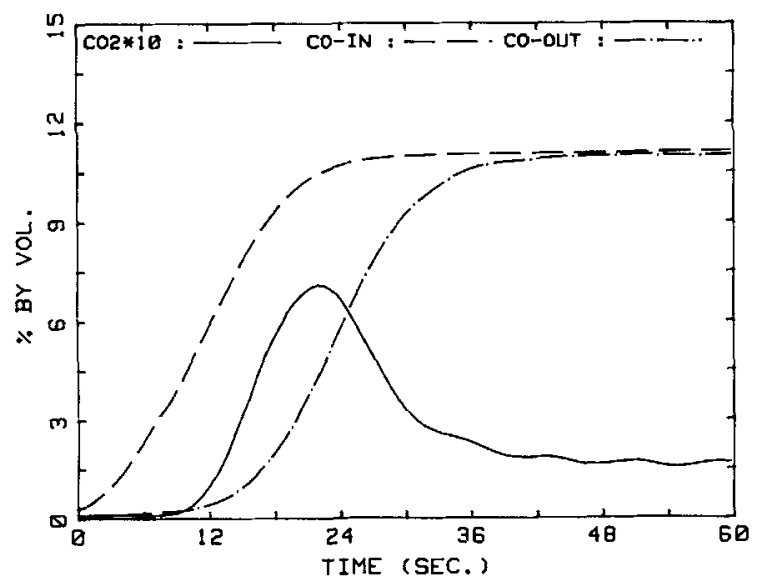

Figure 8. $\mathrm{CO}_{2}$ response to a step-up of $\mathrm{CO}$ in the presence of $\mathrm{O}_{2}$; surface pretreated with $\mathrm{O}_{2}$ for 2 hours. Conditions: $10 \% \mathrm{CO}$ and $10 \% \mathrm{O}_{2}$ in $\mathrm{N}_{2} ; \mathrm{T}=$ $105^{\circ} \mathrm{C}$.

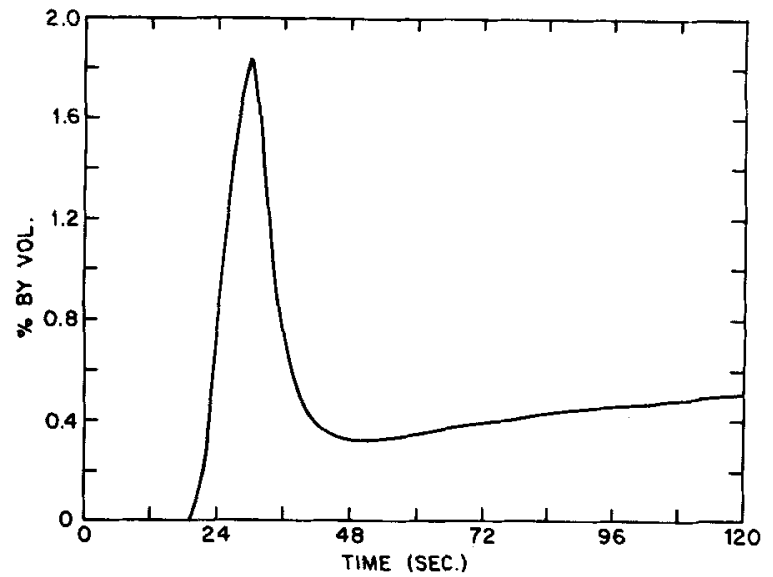

Figure 9. $\mathrm{CO}_{2}$ response to a step-up of $\mathrm{CO}$ in the presence of $\mathrm{O}_{2}$; in order to emphasize overshoot/undershoot behavior, less $\mathrm{O}_{2}$ and higher temperature were used. Conditions: $10 \% \mathrm{CO}$ and $6 \% \mathrm{O}_{2} \ln \mathrm{N}_{2} ; \mathrm{T}=120^{\circ} \mathrm{C}$.

production reaches a maximum of about $1.4 \%$ compared to the steady-state value of $0.21 \%$.

Figure 11 shows a superposition of the $\mathrm{CO}_{2}$ response curve for step-up and step-down of $\mathrm{CO}$ in the presence of $\mathrm{O}_{2}$ to emphasize the difference in the characteristic rise times. It is clear that the step-down response is much more rapid $\left(21.4 \% \mathrm{CO}_{2} / \mathrm{min}\right)$ than the step-up $\left(6.64 \% \mathrm{CO}_{2} / \mathrm{min}\right)$ in the increasing portion of the peak. Based on the above results one can predict that the $\mathrm{CO}_{2}$ production curve will have two peaks per $\mathrm{CO}$ pulse: one at the on-edge and one at the off-edge. Results given in the following sections show that this is indeed the case.

\section{Translent Response}

The first goal in the transient experiments was to determine the relative importance of the ER and $\mathrm{LH}$ mechanisms. For this reason, a higher pressure was used (equal to $140 \mathrm{kPa}$ ) than in previous investigations (Dwyer, 1982). Figures 4 and 5 show that the $\mathrm{CO}_{2}$ response of the system is very similar in shape for either a $\mathrm{CO}$ step-up $\left(\mathrm{O}_{2}\right.$-pretreated catalyst) or an $\mathrm{O}_{2}$ step-up (CO-pretreated catalyst). The positive slopes of the $\mathrm{CO}_{2}$ production peaks were found to be $9.87 \% \mathrm{CO}_{2} / \mathrm{min}$ for the CO-covered catalyst and $6.57 \%$ $\mathrm{CO}_{2} / \mathrm{min}$ for the $\mathrm{O}_{2}$-covered catalyst. If indeed a $\mathrm{CO}$ molecule from the gas phase is reacting with adsorbed $\mathrm{O}_{2}$, its initial rate should be significantly higher than gas phase oxygen reacting with surface $\mathrm{CO}$. This is clearly not the case. The time delay between step-up and the appearance of $\mathrm{CO}_{2}$ at the outlet for both cases is very similar (about 1-2 seconds longer for $\mathrm{CO}$-pretreated catalyst). The $\mathrm{CO}$ and $\mathrm{O}_{2}$ step-up and step-down transient experiments shown in Figures 6 to 10 are interpreted in the following way:

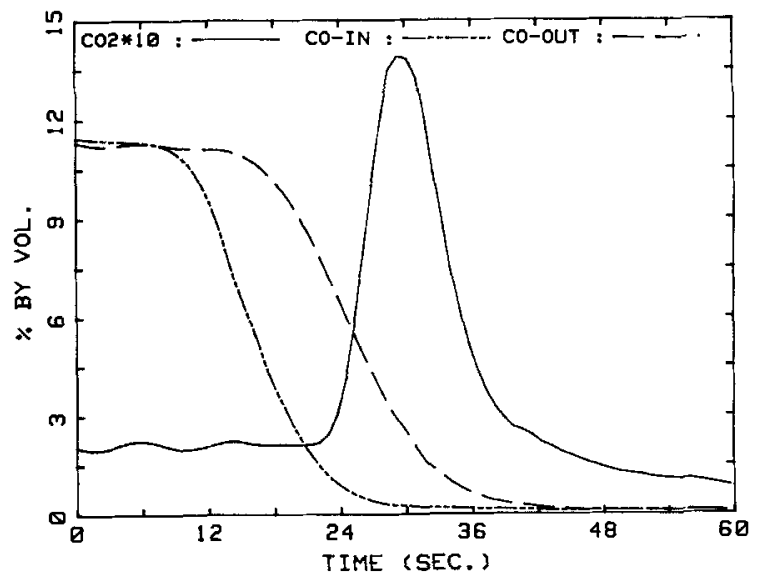

Figure 10. $\mathrm{CO}_{2}$ response to a step-down of $\mathrm{Co}$ from $11.2 \%$ to 0 . Condition: $11.2 \% \mathrm{CO}$ and $10 \% \mathrm{O}_{2}$ in $\mathrm{N}_{2} ; \mathrm{T}=105^{\circ} \mathrm{C}$. 


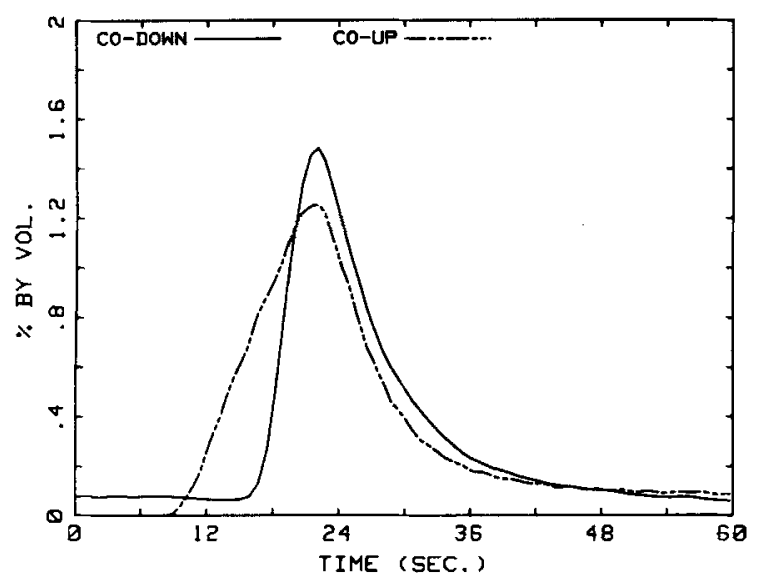

Figure 11. Comparison between the $C O$ response obtained by a $\mathrm{CO}$ step-up and a $\mathrm{CO}$ step-down for an $\mathrm{O}_{2}$-pretreated catalyst, in the presence of $\mathrm{O}_{2}$. Experimental conditions for both cases: $10 \% \mathrm{CO}$ and $10 \% \mathrm{O}_{2}$ in $\mathrm{N}_{2} ; \mathrm{T}=$ $120^{\circ} \mathrm{C}$.

Step-up of $\mathrm{O}_{2}$ in the presence of $\mathrm{CO}$ is the slowest transient of the four. The catalyst is practically covered with $\mathrm{CO}$ in various forms and since adsorption of $\mathrm{O}_{2}$ onto the $\mathrm{CO}$ covered catalyst has a low probability, it takes a relatively long time to consume the reactive $\mathrm{CO}$ and establish $\mathrm{O}_{2}$ sites on the catalyst. $\mathrm{O}_{2}$ step-down results in a much faster response for two reasons: $\mathrm{CO}$ is mobile on the surface while $\mathrm{O}_{2}$ is stationary, and $\mathrm{CO}$ can adsorb on the oxidized surface.

Step-up and -down of $\mathrm{CO}$ in the presence of $\mathrm{O}_{2}$ results in a maximum in the $\mathrm{CO}_{2}$ production rate due to the fact that as the size of $\mathrm{CO}$ islands changes, the total boundary length between the $\mathrm{CO}$ and $\mathrm{O}_{2}$ islands goes through a maximum. Step-down of $\mathrm{CO}$ gives a sharper rise because the $\mathrm{CO}$ is already on the surface and the rate is not slowed down by the adsorption step. For both step-up and step-down the decrease from the maximum rate is exponential with a very similar characteristic decay time.

The $\mathrm{CO}_{2}$ production curve as shown in the $\mathrm{CO}$ step-up experiments exhibits an overshoot/undershoot before reaching steady state (Herz, 1983, observed similar behavior). This oscillation is characteristic of second-order phenomena and indicates a more complicated dependence of the reaction rate on CO coverage than is explainable by first-order kinetics. This is in agreement with the previous observations that adsorbed oxygen is immobile on platinum, whereas $\mathrm{CO}$ molecules adsorb in several forms and are mobile (Haaland, 1982).

If indeed the ER mechanism were playing a significant role in $\mathrm{CO}_{2}$ production, the step-up response should have been steeper than the step-down response because of the gas phase availability of excess $\mathrm{CO}$.

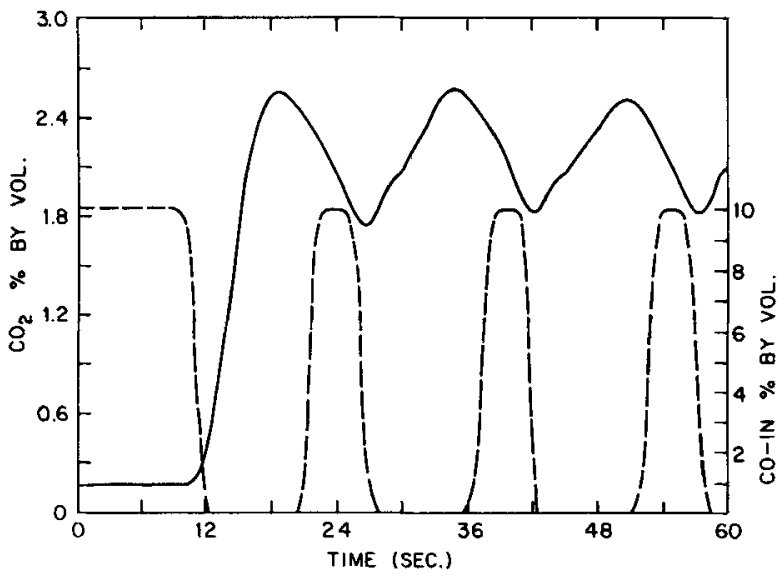

Figure 12. Transition from steady-state to periodlc operation; $15 \mathrm{~s}$ time period and $0.3 \mathrm{CO}$ duty-iraction used to match maximum location for experimental conditions of $10 \% \mathrm{CO}, 10 \% \mathrm{O}_{2}$, and $\mathrm{T}=105^{\circ} \mathrm{C}$.

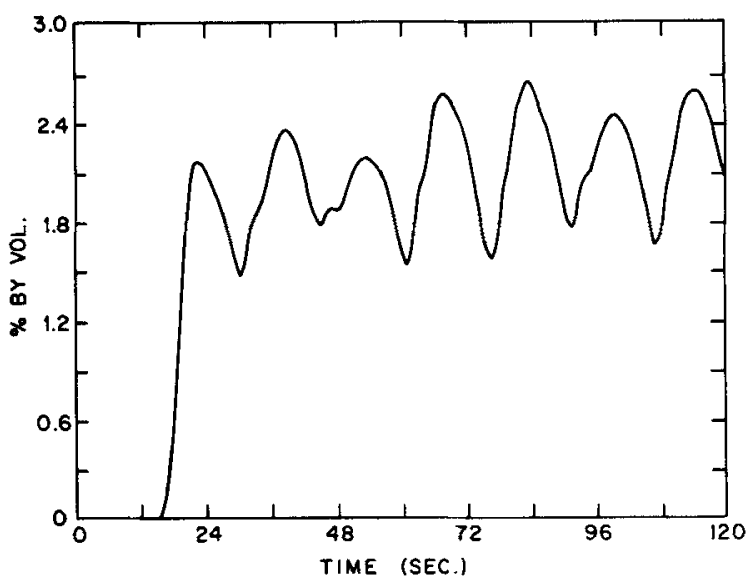

Figure 13. $\mathrm{CO}_{2}$ response for periodic start-up; $15 \mathrm{~s}$ time period, $0.3 \mathrm{Co}$ dutyfraction; surface treated $\mathbf{3 0} \mathrm{min}$ with $\mathrm{CO}$ before swilching to periodic operation. Experimental conditions the same as for Figure 12.

\section{Periodic Operation}

Cutlip (1979) investigated the effect of periodic switching between $3 \% \mathrm{O}_{2}$ and $2 \% \mathrm{CO}$ in a gradientless reactor as a function of the time period and duty-fraction. However, due to equipment limitations he could not operate at periods shorter than one minute (at which he obtained the maximum rate). One of the major aims of this study was to see whether the surface could respond to higher frequencies. While the majority of the results presented here are for $10 \% \mathrm{O}_{2}$ and $\mathrm{CO}$ feed concentrations in $\mathrm{N}_{2}$, different sets of inlet concentrations were also tested.

Figure 12 shows a typical start-up of periodic operation from steady state with time period and $\mathrm{CO}$ duty-fraction equal to the optimum under these conditions ( 15 seconds and 0.3 duty-fraction). Figure 13 shows the start-up for CO-pretreated catalyst for the same temperature and feed conditions (same periodic parameters). As can be seen in Figure 13, the start-up is slower due to CO inhibition and the transients are enveloped in another transient with a one-minute period. Figures 14,15 , and 16 show typical $\mathrm{CO}_{2}$ outlet profiles for periodic operation with time periods equal to 60 , 40 , and 20 seconds. These profiles are in good agreement (for the long time periods) with those obtained by Cutlip (1979) although a different reactor is used. For long switching periods, the rate of $\mathrm{CO}_{2}$ production has two maxima during each period. The first peak is associated with the on-edge of the CO pulse (or the off-edge of the $\mathrm{O}_{2}$ pulse) and the second peak is associated with the off-edge of the CO pulse (or the on-edge of the oxygen pulse). When the period is 60 seconds (Figure 14), for $0.3 \mathrm{CO}$ duty-fraction $\mathrm{CO}_{2}$ production starts increasing immediately with the on-edge of the

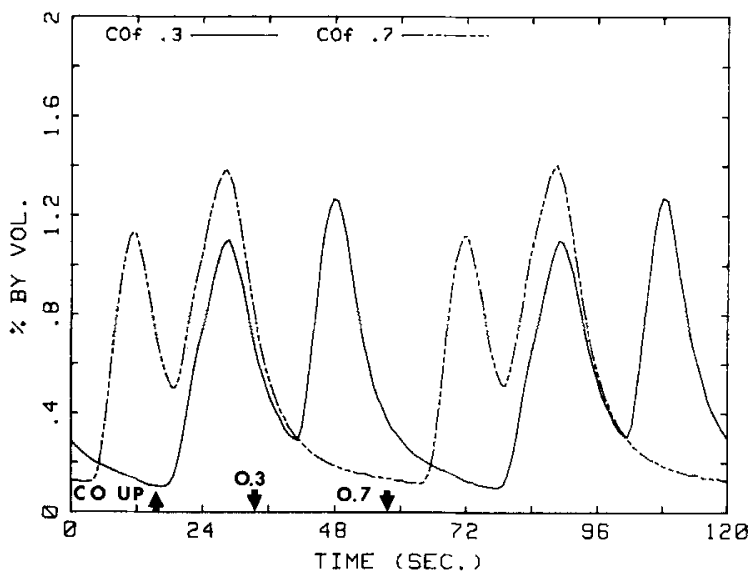

Figure 14. $\mathrm{CO}_{2}$ profiles for perlodic operation; $60 \mathrm{~s}$ time period, 0.3 and 0.7 CO duty-fractions. Experimental conditions: $10 \% \mathrm{CO}$ and $10 \% \mathrm{O}_{2}$ in $\mathrm{N}_{2 ;} ; \mathrm{T}$ $=105^{\circ} \mathrm{C}$. 


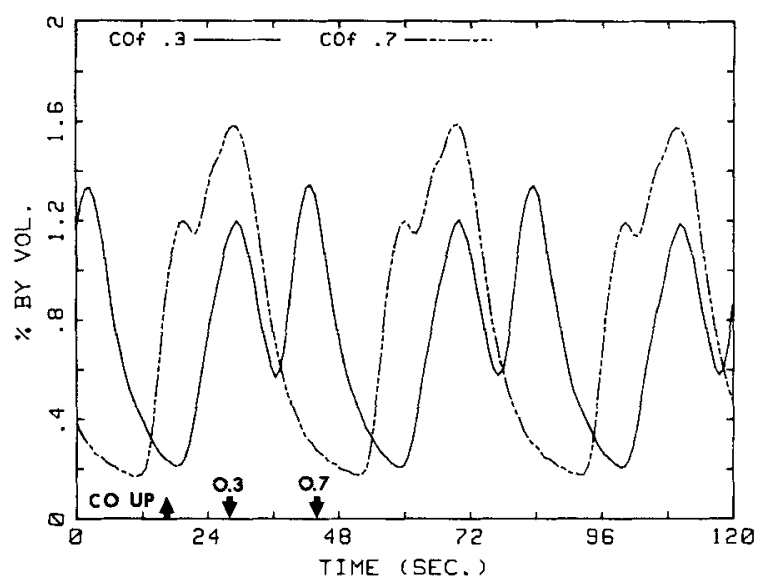

Figure 15. $\mathrm{CO}_{2}$ proflles for periodic operation; $40 \mathrm{~s}$ time period, 0.3 and 0.7 CO duty-fractions. Experimental conditions the same as for Flgure 14.

$\mathrm{CO}$ pulse and reaches a maximum within 9 seconds. After that the rate of production declines exponentially due to the decrease of surface oxygen. As soon as the $\mathrm{CO}$ is switched off and the oxygen is switched on, the $\mathrm{CO}_{2}$ production starts increasing again and reaches a maximum higher than the previous one. Apart from the value of the maximum, the rate of increase of $\mathrm{CO}_{2}$ production for CO-down is 1.85 times the rate of increase observed during the CO-up peak. The higher rate of increase is in qualitative agreement with the CO-up and CO-down experiments shown in Figure 11. With a $0.7 \mathrm{CO}$ duty-fraction, the slope ratio is exactly the same as 0.3. CO-down is 1.85 times steeper than CO-up, but the lower peak is now associated with the CO-down response. The time difference between the high and low peaks for 0.3 duty-fraction is $4.2 \mathrm{~s}$ longer than the 0.7 duty-fraction. One additional point to note in Figure 14 is that the lowest point of $\mathrm{CO}_{2}$ production is identical but the low point between the high and low peaks is $0.5 \%$ for $0.7 \mathrm{CO}$ duty-fraction and $0.3 \%$ for $0.3 \mathrm{CO}$ duty-fraction. Decreasing the time period to 40 seconds resulted in somewhat more interesting $\mathrm{CO}_{2}$ profiles as can be seen in Figure 15. The 0.3 duty-fraction still results in two distinct peaks where the peak associated with $\mathrm{CO}$ down is 1.85 times steeper than the CO-up peak. For CO dutyfraction of 0.7 the two peaks merge and the first peak almost disappears.

The further decrease of the total period to 20 seconds results in dramatic changes (Figure 16). The $\mathrm{CO}_{2}$ production curve for a duty fraction of 0.7 has only a single maximum per cycle period. The rate of $\mathrm{CO}_{2}$ production starts increasing as soon as the oxygen is switched on, and continues increasing until the gas phase $\mathrm{CO}$ reaches its peak value. For a duty-fraction of 0.3 , the $\mathrm{CO}_{2}$ con- centration coming out of the reactor still has two maxima per period; however, the average $\mathrm{CO}_{2}$ concentration is almost constant.

Periodic operation under this feed strategy is basically performing a series of step-up and step-down experiments in order to maintain $\mathrm{CO}_{2}$ production at a level that is as close as possible to the maximum observed during these experiments. While qualitatively appealing, the explanation first proposed by Cutlip (1979) for the increase in reaction rate (that it is due to equal surface coverage by both $\mathrm{CO}$ and $\mathrm{O}_{2}$ ) cannot explain more than a tenfold increase in the rate. By manipulating the gas phase concentrations under reacting conditions one can obtain any desired surface coverage ratio of $\mathrm{CO}$ to $\mathrm{O}_{2}$. It has been shown (Voltz, 1973) that indeed there is a gas phase concentration that will result in a maximum $\mathrm{CO}_{2}$ production and that it is at a point where the reaction order is zero with respect to $\mathrm{CO}$ (shifts from +1 to -1 ). It is important to note that our steady-state experiments were conducted at this point.

The enormous rate improvements obtained under periodic operation can be understood from the arguments used to explain the transients presented in Figures 14-16. During each period numerous $\mathrm{CO}$ islands are formed which increase in number and size when $\mathrm{CO}$ is on, and decrease in size (and increase in number) when $\mathrm{CO}$ is off. During the on and off cycles the total perimeter-to-area ratio goes through a maximum, resulting in a maximum rate of reaction. Changing the time period and $\mathrm{CO}$ duty-fraction maximizes the reaction rate by optimizing this ratio.

The slopes observed in the $\mathrm{CO}_{2}$ production profiles are complex functions of adsorption, surface diffusion, and reaction. For this reason, overlapping of peaks occur and interpretation in terms of peaks associated with CO-up and -down has little benefit. An interesting point to note is that in our step tests we observed that the amount of $\mathrm{CO}_{2}$ produced during a $\mathrm{CO}$ step (oxygen-pretreated) was almost twice that of the $\mathrm{O}_{2}$ step (CO-pretreated), whereas in periodic operation the amount of $\mathrm{CO}_{2}$ produced is almost equal during the oxygen or $\mathrm{CO}$ pulses for long periods.

Figures 17,18 and 19 demonstrate the ability of our computerized system to deal with large amounts of data. They are isoconversion maps in the time-period, duty-fraction plane. At constant temperature, pressure, and steady-state feed compositions, the CO duty-fraction and time period were changed systematically. At each value of time period and duty-fraction the reactor was operated until steady periodic operation was achieved. At that point the $\mathrm{CO}_{2}$ concentration was integrated with respect to time and the time-average concentration was calculated. Figure 17 for example contains 108 such integrations.

We see that even in a tubular reactor, periodic operation provides more than a tenfold improvement over steady-state operation. As can be seen in the contour maps, the rate increases steeply for short time-periods at constant $\mathrm{CO}$ duty-fraction and then slowly de-

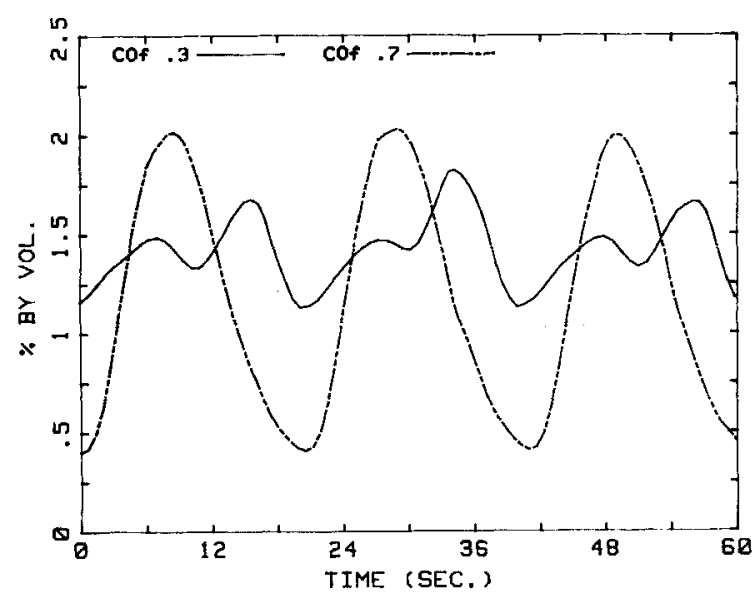

Figure 16. $\mathrm{CO}_{2}$ profiles for periodic operation; $20 \mathrm{~s}$ time perlod, 0.3 and 0.7 CO duty-fractions. Experimental conditions the same as for Figure 14.

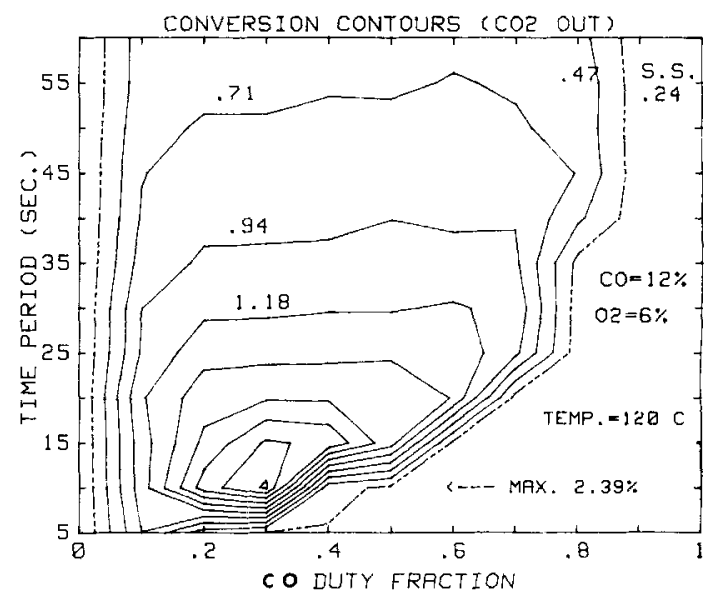

Figure 17. Conversion contours of average $\mathrm{CO}_{2}$ outlet concentration; experimental array contains 108 individual experiments. 


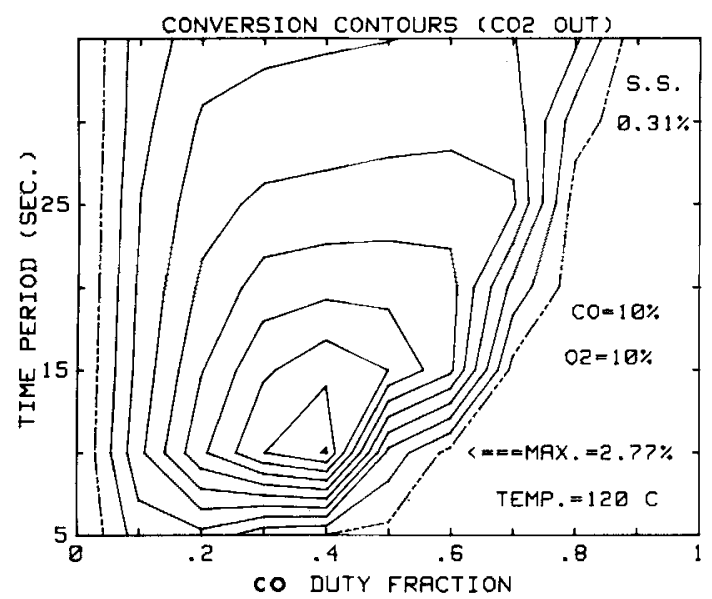

Figure 18. Conversion contours of average $\mathrm{CO}_{2}$ oullet concentration; experimental array contains 72 indlvidual experiments.

creases. At constant time period and increasing duty-fractions the average rate increases, reaches a maximum, and then sharply decreases. The area of fast deterioration drifts to high CO dutyfractions irrespective of gas phase concentrations and reaches a value of about 0.6 duty-fraction. This may indicate that exposure time is as important as duty-fraction and time period. Presently, we are not sure about the physical significance of this finding, but it seems to be independent of system and temperature.

In Figure 20, we show how the location of the maximum moves in the time-period, duty-fraction plane for three temperatures. We see that as the temperature increases, the optimum period gets shorter. This is explained by the fact that the surface reaction rates will increase with temperature and thus less time will be required to consume the reactants on the surface. Changing the $\mathrm{CO} / \mathrm{O}_{2}$ ratio in the feed does not change the optimal time period but does change the duty-fraction.

When the temperature and the steady-state feed concentrations are fixed, finding the optimum time period and CO duty-fraction requires a two-dimensional search. To our knowledge, Figure 17 represents the first experimental determination of the optimum period and $\mathrm{CO}$ fraction. There are several important observations to be made from Figures 17, 18 and 19:

1) The conversion curve has a single global maximum.

2) At the optimum periodic operation point, the time-average conversion is 10,9 , and 15 times the maximum achievable under steady state.

3) Except at extreme duty-fractions (duty-fraction above 0.9 and below 0.03 ), periodic operation always results in higher average conversion.

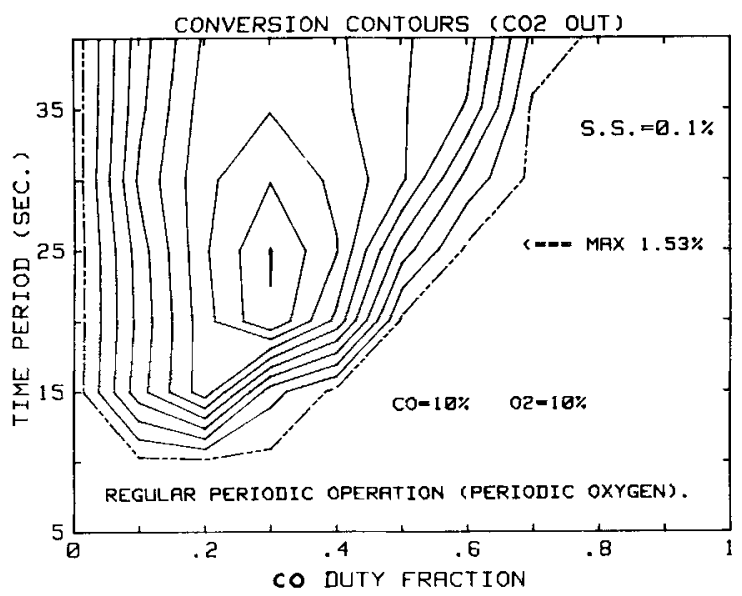

Figure 19. Conversion contours of average $\mathrm{CO}_{2}$ outlet concentration; experimental array contains 63 individual experiments; $T=90^{\circ} \mathrm{C}$.

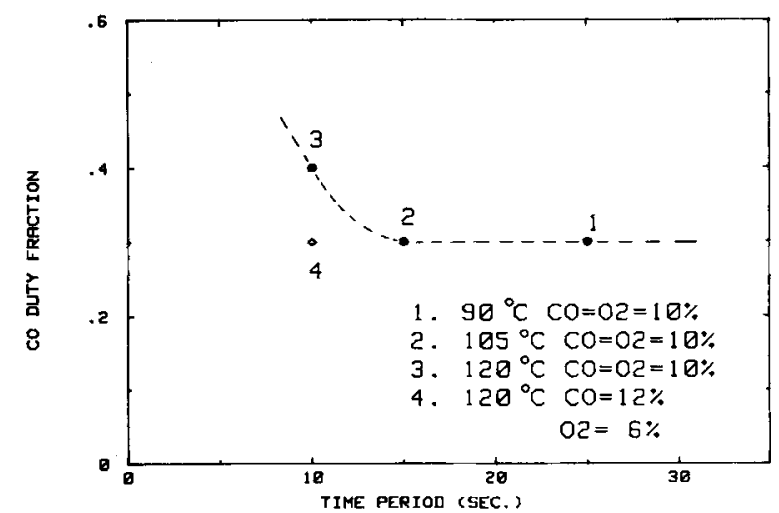

Figure 20. Location of maxima for four mapping experiments; three for equal concentrations at different temperatures, one for the stoichlometric point.

4) At the optimal periodic operation point, conversion decreases dramatically with decreasing switching period. This is due to the fact that for switching periods less than the characteristic time of the surface reaction and the reactor, the reactor is operating at a "relaxed steady state," averaging the concentration profiles.

5) For switching periods longer than the optimum, conversion varies slowly with switching period.

6) For switching periods longer than the optimum, the maximum in conversion occurs for a duty-fraction greater than the duty-fraction of the optimum (i.e., the catalyst needs to be exposed to CO for longer periods of time).

The location of the point of maximum conversion moves in a systematic fashion with temperature. As shown in Figure 20, low temperatures favor lower CO duty-fractions and longer time periods. An increase in the gas phase oxygen concentration does not change the optimum period but rather increases the optimum $\mathrm{CO}$ duty-fraction.

Periodic feeding of only one of the reactants is experimentally easier than periodic feeding of both reactants. To our knowledge this feed strategy has not been tried in previous CO oxidation studies. Figure 21 shows an isoconversion contour map for this kind of feed strategy. This figure can be compared to Figure 19 where both $\mathrm{O}_{2}$ and $\mathrm{CO}$ were switched on and off under identical conditions. Continuous feeding of $\mathrm{O}_{2}$ results in a 19-fold increase in the average rate of reaction over that of steady state. In comparison, switching both $\mathrm{CO}$ and $\mathrm{O}_{2}$ results in a 15 -fold increase. Figure 22 shows the concentration profiles of $\mathrm{CO}$ and $\mathrm{CO}_{2}$ at the outlet for the optimum point of operation. Just as in Figures 14-16, there are two maxima per period in the $\mathrm{CO}_{2}$ production. However, the height of the peak occurring when $\mathrm{CO}$ is off is much less than the

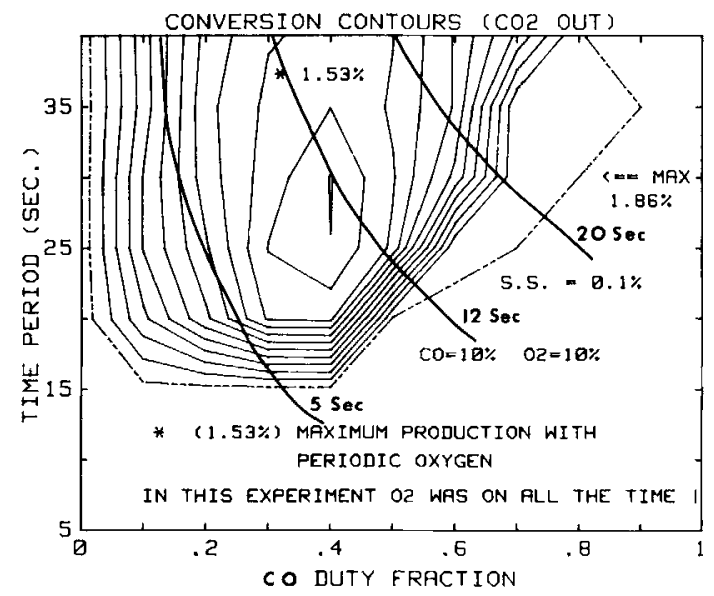

Figure 21. Conversion contours for a case with constant $\mathrm{O}_{2}$ flow into reactor and $\mathrm{CO}$ switched on and off. Thick solid lines $=$ constant $\mathrm{CO}$ pulse lengths of 5,12 , and 20 s; $T=90^{\circ} \mathrm{C}$. 


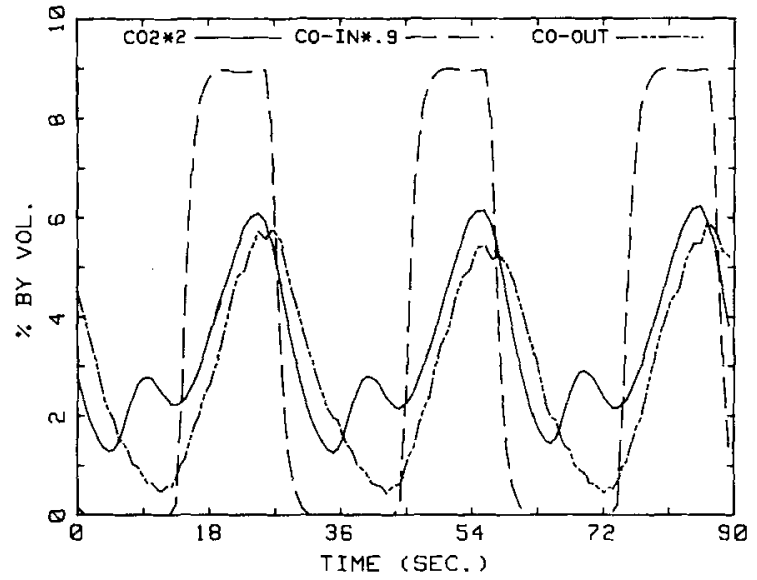

Figure 22. Inlet $\mathrm{CO}$, oullet $\mathrm{CO}$, and $\mathrm{CO}_{2}$ profiles in perlodic carbon monoxide operation with constant $\mathrm{O}_{2}$ flow into reactor.

peak in phase with the CO pulse. Comparison of Figure 21 (periodic switching of $\mathrm{CO}$ only) with Figure 19 obtained under exactly the same experimental conditions shows that the maximum attainable time-averaged rate of reaction is about $22 \%$ higher. Also, the optimum CO pulse is longer by $30 \%$. Both of these are to be expected since the effective gas phase concentration is higher when oxygen is fed continuously. A subtle difference is the location of the region of steepest descent in the time-averaged rate. Compared to all the other isoconversion maps, this region is shifted to the right of the maximum. When only the $\mathrm{CO}$ feed is periodic the same $\mathrm{CO}$ pulse length is obtained with different total periods. In Figure 21 we show three lines of constant CO pulse length. From the intersection of these lines with the isoconversion curves one can determine the transition from the $\mathrm{CO}$-limited region to the $\mathrm{O}_{2}$-limited region. For a 5-second-long $\mathrm{CO}$ pulse the time-averaged rate is almost independent of the total period for periods longer than 30 seconds. There is a gentle rise in the rate until a total period of 20 seconds is reached, after that there is a very steep decrease as the reaction becomes oxygen-limited. Essentially the same observations apply to constant $C O$ pulses 12 and 20 seconds long except that the location of the maximum rate and the region of steepest descent due to oxygen limitation moves to longer time-periods.

A common feature of all four contour maps is that the timeaveraged rate is almost independent of the total period for $\mathrm{CO}$ duty-fractions less than the optimum. For higher CO duty-fractions there is a weak but clear dependence on the time period.

An interesting difference between the constant oxygen feed and periodic oxygen feed strategies is seen upon comparison of Figures 22 and 16. In Figure 16 we see that the $\mathrm{CO}_{2}$ production rate has two peaks per period, but overall the production rate is almost constant. In Figure 22 on the other hand, there are two peaks per period with the maximum about $50 \%$ higher than the average rate. There is a large $\mathrm{CO}_{2}$ production peak which is in phase with the $\mathrm{CO}$ pulse coming out of the reactor. The maximum is reached very close to the end of the CO pulse, and as a result all the $\mathrm{CO}$ on the surface is consumed rapidly. The $\mathrm{CO}_{2}$ production rate increases rapidly when there is no $\mathrm{CO}$ coming into the reactor, but due to the low amount of $\mathrm{CO}$ stored by the surface the maximum in the rate is lower than the maximum in phase with the CO pulse. This difference is to be expected since our step-up and -down experiments showed that the $\mathrm{CO}_{2}$ production pulse is almost twice as large when the surface is pretreated with oxygen compared with CO pretreatment.

In order to verify that the increases in the time averaged rate of reaction were not due to creation of hot spots, the diluent gas was changed from $\mathrm{N}_{2}$ to $\mathrm{He}$, which has a thermal conductivity 5.3 times that of nitrogen, and some of the experiments were repeated. No significant changes in the operation of the reactor were observed. Numerical computations indicate that under our operating conditions it is impossible to reach the temperatures required for ignition. Also no measurable temperature excursions were observed when a fast-response (milliseconds) thermocouple was imbedded in the reactor.

The experimental results obtained when only $\mathrm{CO}$ was switched on and off also confirm the absence of ignition. As can be seen in Figure 22, the $\mathrm{CO}_{2}$ outlet concentration peaks up before the $\mathrm{CO}$ outlet concentration, and the maximum conversion is only $3 \%$. If we had had ignition the maximum should have been $10 \%$.

\section{ACKNOWLEDGMENT}

We would like to thank Dr. R. K. Herz of General Motors research laboratories for supplying the catalyst and for his valuable criticism of the initial draft of this manuscript. We would also like to acknowledge discussions with Dr. M. B. Cutlip. Financial support of this study was provided by NSF grant CPE7920818, DMR8100130, and ACS-PRF13210-AC7-C.

\section{LITERATUAE CITED}

Al-Taie, A. S., and L. S. Kershenbaum, "Effect of Periodic Operation on the Selectivity of Catalytic Reactions," ACS Symp. Ser., 65, 512 (1978).

Bailey, J. E., "Periodic Operation of Chemical Reactors: A Review," Chem. Eng. Comm., 111 (1973).

- , "Periodic Phenomena," Chemical Reactor Theory, A Review, L. Lapidus and N. R. Amudson, Eds., 758, Prentice-Hall, Englewood Cliffs, NJ (1977)

Bennett, C. O., "The Transient Method and Elementary Steps in Heterogeneous Catalysis," Catal. Rev. Sci. Eng., I3(2), I2I (1976).

Bilimoria, M. R., and J. E. Bailey, "Dynamic Studies of Acetylene Hydrogenation on Nickel Catalysts," ACS Symp. Ser., 65, 526 (1978).

Carberry, J. J., Chemical Reaction Engineering, McGraw-Hill, New York (1976).

Cutlip, M. B., "Concentration Forcing of Catalytic Surface Rate Processes," AIChE J., 25, 502 (1979).

- "Modelling of Forced Periodic Oscillations of CO Oxidation Over Platinum Catalyst," Paper 57F, AIChE Meet., Los Angeles (1982).

Cutlip, M. B., and C. N. Kenney, "Limit Cycle Phenomena During Catalytic Oxidation Reactions Over a Supported Platinum Catalyst," ACS, Symp. Ser., 65, 475 (1978).

Denis G. H., and R. L. Kabel, "The Effect on Conversion of Flow Rate Variations in a Heterogeneous Catalytic Reactor," 16, 972 (1970).

Douglas, J. M., Process Dynamic and Control, Vol. 2, Prentice-Hall, Englewood Cliffs, NJ (1972).

_- "Periodic Reactor Operation," IEEC Proc. Des. Dev., 6, I, 42 (1967).

Douglas, J. M., and D. W. T. Rippin, "Unsteady State Process Operation," Chem. Eng. Sci., 21, 305 (1966).

Dwyer, S. M., and C. O. Bennett, "Transient Infrared Studies of Carbon Monoxide Oxidation on a Supported Platinum Catalyst," J. Catal., 75, 275 (1982).

Engel, T., and G. Ertl, in Advances in Catalysis, Vol. 28, W. G. Frankenburg, V. I. Komarewsky, and E. K. Rideal, Eds., Academic Press, New York (1979).

Fair, J., and R. J. Madix, "Molecular Beam Investigation of the Oxidation of CO on Pt $\left(9(111)^{*}(100)\right)$," J. Chem. Phys., 73, 3,486 (1980).

Gland, J. L., G. B. Fisher, and E. B. Kollin, "The Hydrogen-Oxygen Reaction Over the Pt(111) Surface: Transient Titration of Adsorbed Oxygen with Hydrogen," J. Catal., 77, 263 (1982).

Haaland, D. M., and F. L. Williams, "Simultaneous Measurement of CO Oxidation Rate and Surface Coverage on $\mathrm{Pt} / \mathrm{Al}_{2} \mathrm{O}_{3}$ Using Infrared Spectroscopy: Rate Hysteresis and CO Island Formation," J. Catal., 76, $450(1982)$.

Herz, R. K., and S. P. Marin, "Surface Chemistry Models of Carbon Monoxide Oxidation on Supported Platinum Catalysts," J. Catal., 65, 281 (1980).

Herz, R. K., "The Dynamic Behavior of Three-Way Automotive Catalysts," ACS Symp. Ser., 178, 59 (1982). 
Herz, R. K., and E. J. Shinouskis, "Transient Oxidation and Reduction of Alumina-Supported Platinum," Presented at Matls Res. Soc., Boston (Nov., 1983).

Jain, A. K., P. L. Silveston, and R. R. Hudgins, "Forced Composition Cycling Experiments in a Fixed-Bed Ammonia Synthesis Reactor," ACS Symp. Ser., 196, 109 (1982).

Kobayashi M., "Characterization of Transient Response Curves in Heterogeneous Catalysis," Chem. Eng. Sci., 37, 3, 393 (1982).

Kobayashi, H., and M. Kobayashi, "Transient Response Method in Heterogeneous Catalysis," Catal. Rev. Sci. Eng., 10(2), 139 (1974).

Renken, A., H. Helmrich, and K. Schugerl, "Beinflussung der effektiven Geschwindigkeit heterogenkatalytisher Reactionen durch aufgezungene Konzentrationschwan kungen," Chem. Ingr. Techn., 46, 647 (1974)

Renken, A., M. Mueller, and C. Wondrey, "Experimental Studies on the Improvement of Fixed-Bed Reactor by Periodic Operation-The Catalytic Oxidation of Ethylene," Proc. 4th Int. 16th Eur. Symp. Chem. Reac. Eng., Dechema, Frankfurt (1976).

Rinker R. G., and H. D. Wilson, "Concentration Forcing in Ammonia Synthesis," Chem. Eng. Sci., 37, 3, 343 (1982).

Sarakany J., M. Bartok, and R. D. Gonzalez, "The Modification of CO
Adlayers on $\mathrm{Pt} / \mathrm{SiO}_{2}$ Catalysts by Preadsorbed Oxygen; An Infrared and Pulse Microreactor Study," J. Catal., 81, 347 (1983).

Satterfield, C. N., Heterogeneous Catalysis in Practice, McGraw-Hill, New York (1981).

Scheintuch, M., and R. A. Schmidtz, "Oscillations in Catalytic Reactions," Cat. Rev. Sci. Eng., 15, 107 (1977).

Tamaru K., "Adsorption Measurements During Catalysis," Adv. in Catal., $15,65(1964)$.

Tsotsis, T. T., and A. E. Elhaderi, "Reaction Rate Oscillations During the Carbon Monoxide Oxidation Reaction Over $\mathrm{Pt} / \mathrm{Al}_{2} \mathrm{O}_{3}$ Catalysts: An IR-Transmission Spectroscopy Study," ACS Symp. Ser., 196, 77 (1982).

Unni, M. P., R. R. Hudgins, and P. L. Silveston, "Influence of Cycling on the Rate of $\mathrm{CO}$ Oxidation of $\mathrm{SO}_{2}$ Over a Vanadia Catalyst," Can J. Chem. Eng., 51, 623 (1973).

Voltz, S. E., et al., Ind. Eng. Chem. Prod. Res. Dev, 12, 294 (1973)

Wei, J., "The Catalytic Muffler," Adv. in Chem. Ser., 148, 1 (1975).

Manuscript received May 11, 1983; revision received Jan. 17, 1984, and accepted Jan. 28 